\title{
Buckling Load Predictions of Panel and Shell using Vibration Correlation Technique
}

\author{
Nayani Uday Ranjan Goud, Alka Sawale, Bhupal Rakham
}

\begin{abstract}
Prediction of buckling loads is a very important phenomenon for aerospace and marine industry. In this paper buckling predictions of a submarine hull is considered by using a shell element and a rectangular panel is considered by using a plate element. The buckling load of a submarine hull can be predicted by using vibration correlation technique. Determination of these buckling loads can be carried out based on the boundary conditions of the submarine hull structure. The technique will be carried by considering both surface conditions and to determine the crippling load of a hull. This paper aims to use VCT for a submarine hull structure used in marine, ocean and can compare the results to aerospace industry by considering a rectangular panel for which buckling is predicted using vibration correlation technique. VCT is not very extensively used in case of thermal buckling. However in this paper, VCT is applied to verify the thermal buckling of a simple thin rectangular panel subjected to parabolic loading.
\end{abstract}

Keywords: Buckling, Thermal buckling, Vibration correlation technique.

\section{INTRODUCTION}

Composite laminated plates are widely used in aerospace industries, ship industries and civil applications because of their strength to weight, strength to stiffness ratio. It is essential to find the buckling strength of these plates as these are subjected to axial forces in practice [1]. The natural frequencies of a structure can be estimated through vibration correlation technique. The change in the natural frequencies is then observed by enhancing the applied load. The buckling loads and vibrational modes are identical to each other; therefore a curve can be plotted between the applied load and square of the natural frequencies. Buckling loads of the structure are then estimated from the sequence of values from the curve to zero frequency [2]. VCT is successfully applied to various structures yield a straight line has been driven between the frequencies which is squared at the compressive load [2]. The material selection for the manufacturing process of SPFRC is made of two Al6063-T6 above and below of

Revised Manuscript Received on December 30, 2019.

* Correspondence Author

Nayani Uday Ranjan Goud*, Assistant Professor, Department of Aeronautical Engineering, MLR Institute of Technology, Dundigal, Hyderabad (Telangana) India. E-mail: udayaero@gmail.com

Alka Sawale, Assistant Professor, Department of Aeronautical Engineering, MLR Institute of Technology, Dundigal, Hyderabad (Telangana) India. E-mail: alkasawale@gmail.com

Bhupal Rakham, Assistant Professor, Department of Aeronautical Engineering, MLR Institute of Technology, Dundigal, Hyderabad (Telangana) India. E-mail: bhupalrakham@gmail.com

(C) The Authors. Published by Blue Eyes Intelligence Engineering and Sciences Publication (BEIESP). This is an open access article under the CC BY-NC-ND license (http://creativecommons.org/licenses/by-nc-nd/4.0/) eleven various configurations of glass fiber layers to form as a sandwich panel. [3]

This relationship can be written as:

$$
\left(\mathrm{f} / \mathrm{f}_{\mathrm{o}}\right)^{2}+\left(\mathrm{P} / \mathrm{P}_{\mathrm{o}}\right)^{2}=1-
$$

Where $\mathrm{f}$ and $\mathrm{P}$ are natural frequency (in $\mathrm{Hz}$ ) and the applied compressive load, respectively, $\mathrm{f}_{\mathrm{o}}$ is the natural frequency at zero and $\mathrm{P}_{\mathrm{o}}$ is the buckling load of the structure.

The results of any thin walled structure or model can be validated through non destructive testing methods which are the important experimental methods performed for most of the aerospace structures problems. Various critical loads can be estimated for different types of structures by considering appropriate boundary conditions of a particular problem wherein vibration correlation plays an important technique to estimate these boundary conditions [3]. VCT is specifically important for under water systems as the design is mostly buckling dominated, in this the work is carried out to apply vibration correlation techniques on a submarine hull. Vibration correlation technique is then applied to thermal buckling, which is a frequent phenomenon in aerospace structures.

\section{METHODOLOGY}

\section{VCT applied to Submarine hull}

A shell element(2 node 188 of ANSYS) is used to construct a cylinder of radius $5 \mathrm{~m}$, depth $4 \mathrm{~m}$ and thickness $0.05 \mathrm{~m}$. The Hull thus formed is clamped on one side and fixed in $\mathrm{x}$ and $\mathrm{y}$ direction on the other side. The Pressure loads applied on nodes of the Hull and are gradually increased to monitor the frequency changes. Buckling loads and the vibrational modes are identical and therefore we can plot a graph between the applied loads and the natural frequencies that render us to estimate the buckling loads of any type of structure.
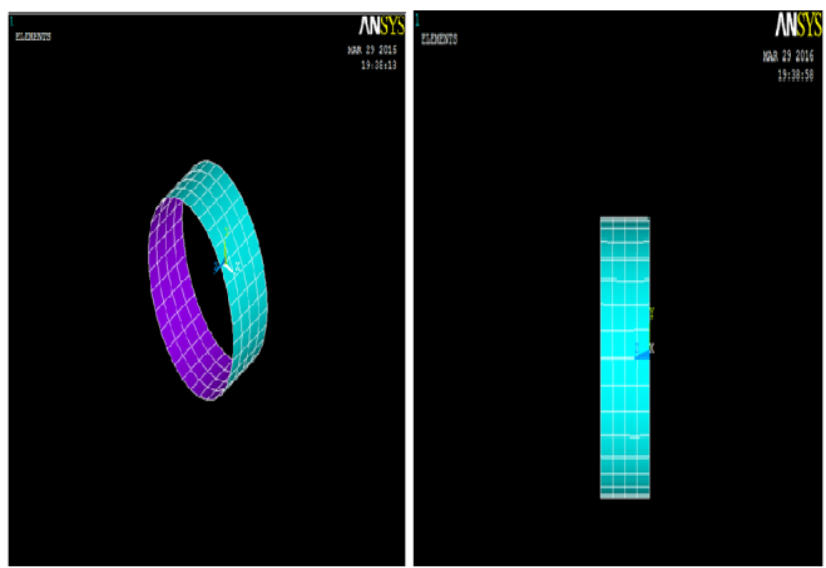

Fig 1: Meshed cylinder-Isometric view and side view 


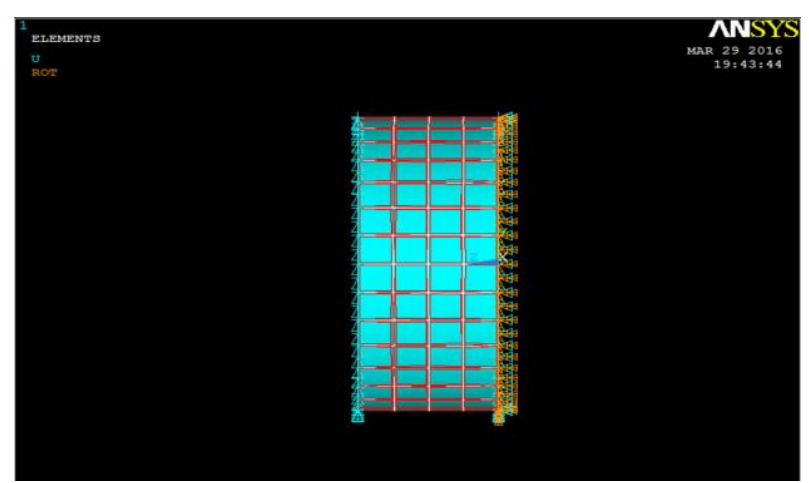

Fig 2: Hull with displacement loads and applied pressure loads

Table-I: Load vs frequency^ 2 for the given submarine hull

\begin{tabular}{|r|r|r|}
\hline $\boldsymbol{\omega}(\mathrm{Hz})$ & Pressure load(Pa) & \multicolumn{1}{c|}{$\boldsymbol{\omega}^{\wedge}$} \\
\hline 57.215 & 1 & 3273.556 \\
\hline 57.188 & 5000 & 3270.467 \\
\hline 57.161 & 10000 & 3267.38 \\
\hline 56.943 & 50000 & 3242.505 \\
\hline 56.669 & 100000 & 3211.376 \\
\hline 54.292 & 500000 & 2947.621 \\
\hline 50.347 & 1000000 & 2534.82 \\
\hline 46.065 & 1500000 & 2121.984 \\
\hline 41.342 & 2000000 & 1709.161 \\
\hline 35.51 & 2500000 & 1260.96 \\
\hline 27.016 & 3000000 & 729.8643 \\
\hline 9.61 & 3600000 & 92.3521 \\
\hline 6.2731 & 3650000 & 39.35178 \\
\hline 2.735 & 3680000 & 7.480225 \\
\hline 0 & 3690000 & 0 \\
\hline 0 & 3700000 & 0 \\
\hline & & \\
\hline 0 & &
\end{tabular}

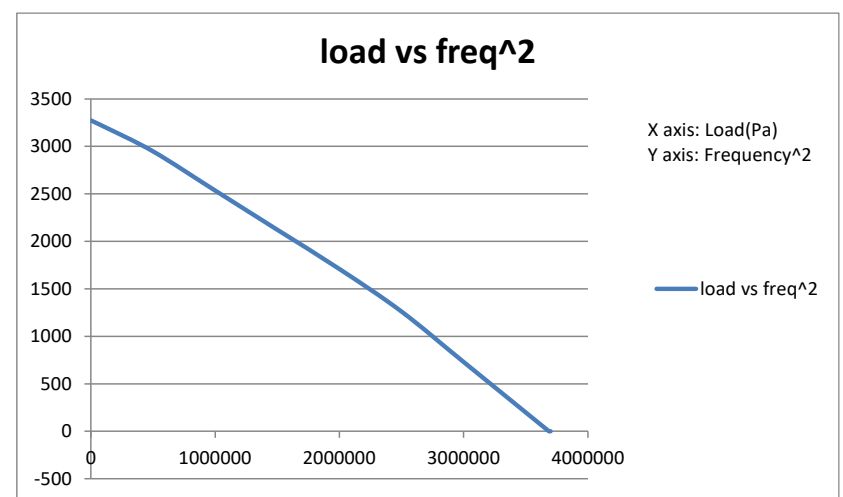

Fig3: Graph of load (x-axis) vs frequency squared (y-axis) of a hull

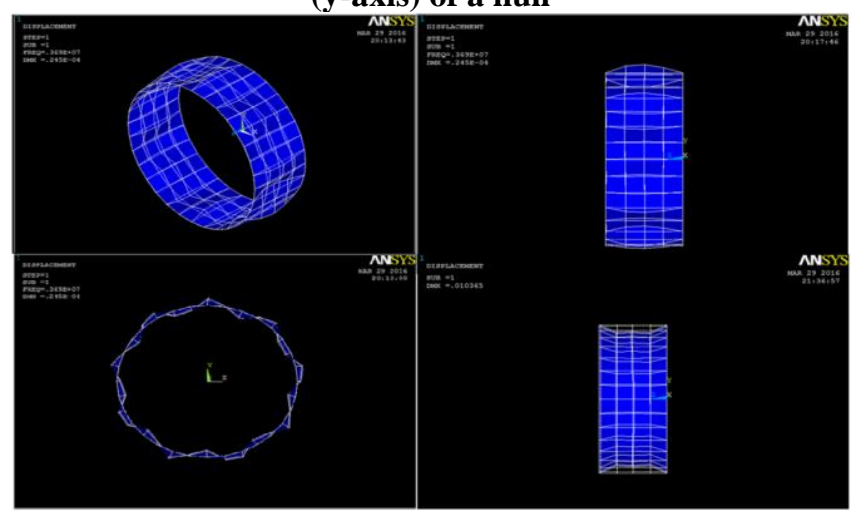

Fig 4: Deformed shape of a hull due to buckling-Isometric view, side view, and top view (clockwise).
The frequency becomes zero when the applied pressure reaches $3.7 \mathrm{e} 07 \mathrm{~Pa}$ relatively equal to the crippling load 3.6861e+06Pa obtained from the Eigen buckling (ANSYS).

\section{ANALYSIS USING ANSYS}

A shell element (8 node 181 of ANSYS) is used to make 0.25 $\mathrm{X} 0.25 \mathrm{~m}^{2}$ panel of $0.00232 \mathrm{~m}$ thickness and it is clamped on all sides as the edges in the aircraft panel are attached to a heat sink and according to that we assign thermal loads, in such a way that the temperature at the edges are zero and slowly the temperature increases as we move to center [6]. An equivalent model of the stiffened panel majorly used to study post behavior structure of buckling and its panel failure. The safeguard must be taken while applying load across the edge. We see different deformations for different modes, below are the different modes and deflections at $\mathrm{T}=10^{\circ} \mathrm{C}$.

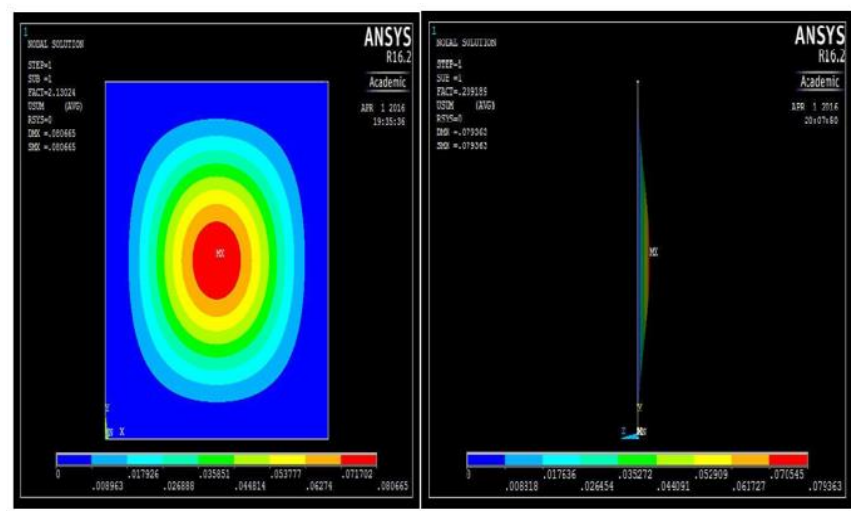

Fig 5: Mode1 front view and side view.

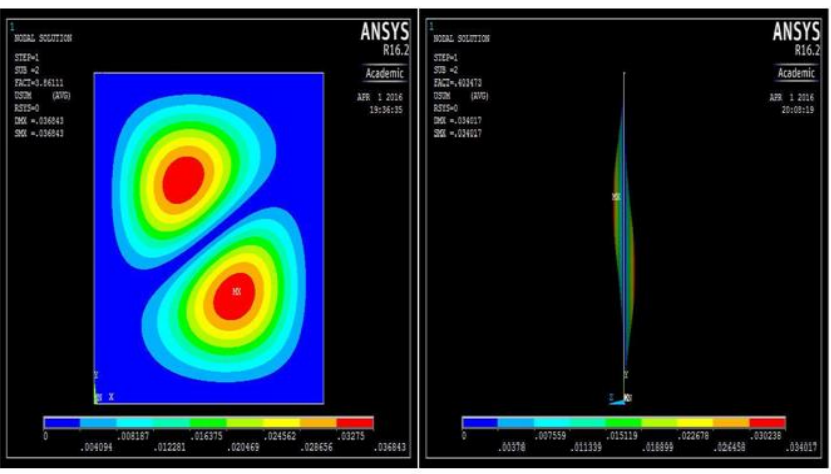

Fig 6: Mode2 front view and side view.

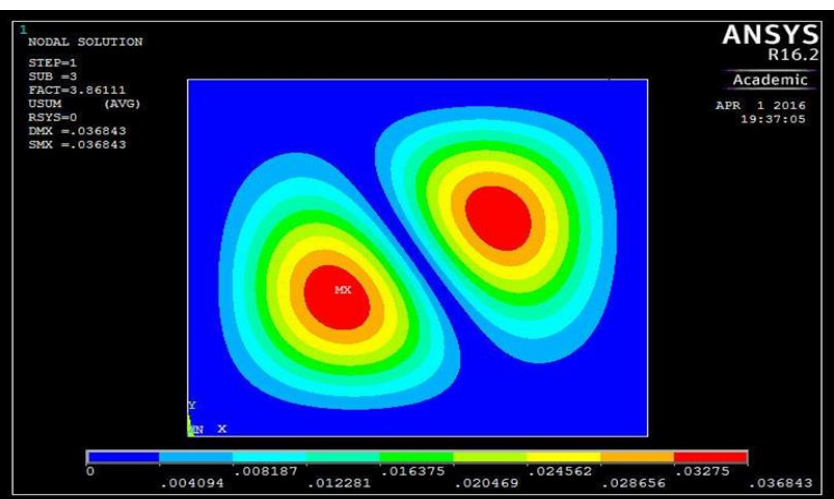

Fig 7: Mode3 front view.

Published By:

Blue Eyes Intelligence Engineering \& Sciences Publication

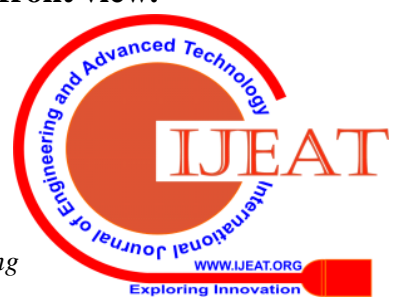



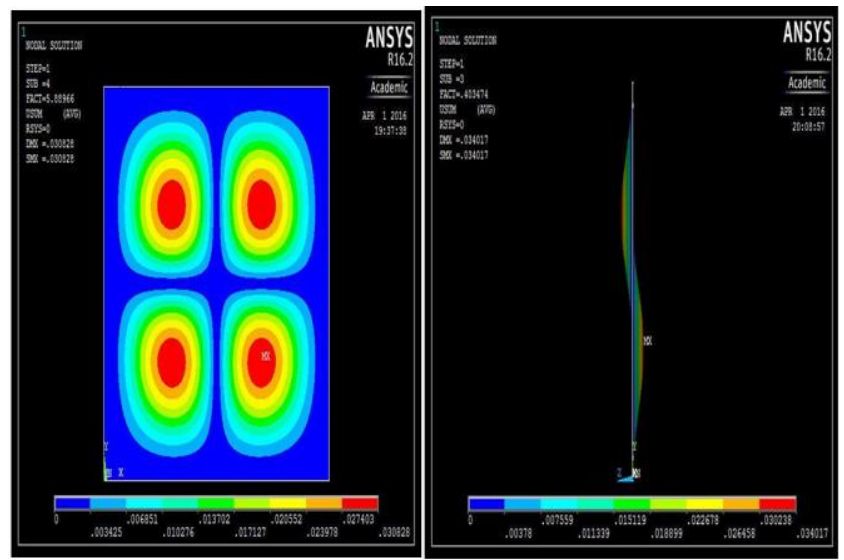

Fig 8: Mode4 front view and side view.

We take the frequency values by going to general postproc $>$ read results $>$ by pick

We get the following value for $\mathrm{T}=10^{\circ} \mathrm{C}$.

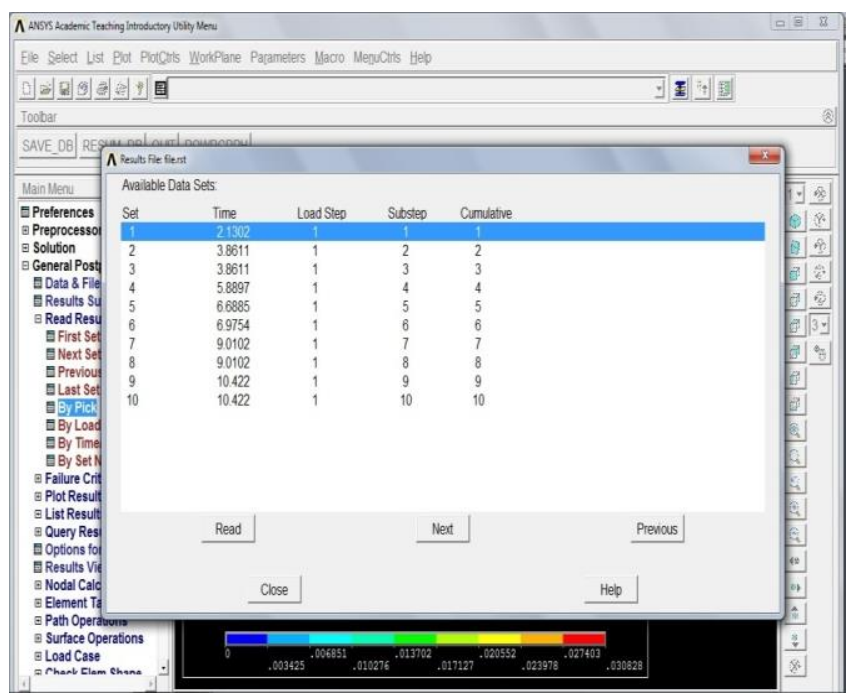

Fig 9: frequency values for $\mathrm{T}=10^{\circ} \mathrm{C}$.

Similarly, we find out the frequency values for different thermal loads. And plot the graph correlating the thermal loads and the frequency.

Table-II: load vs frequency ${ }^{\wedge} 2$ for the plate with thermal buckling.

\begin{tabular}{|r|r|r|r|r|}
\hline Temperature $\left.^{\circ}{ }^{\circ} \mathrm{C}\right)$ & mode 1 & mode 2 & mode 3 & mode 4 \\
\hline 0 & 4.61 & 9.35 & 9.35 & 14.12 \\
\hline 10 & 2.13 & 3.86 & 3.86 & 5.88 \\
\hline 20 & 1.0042 & 1.74 & 1.74 & 2.65 \\
\hline 30 & 0.655 & 1.12 & 1.12 & 1.7 \\
\hline 40 & 0.48 & 0.82 & 0.82 & 1.25 \\
\hline 50 & 0.4 & 0.72 & 0.72 & 1.12 \\
\hline 60 & 0.38 & 0.65 & 0.65 & 0.99 \\
\hline 70 & 0.32 & 0.54 & 0.54 & 0.82 \\
\hline 80 & 0.231 & 0.403 & 0.403 & 0.613 \\
\hline
\end{tabular}

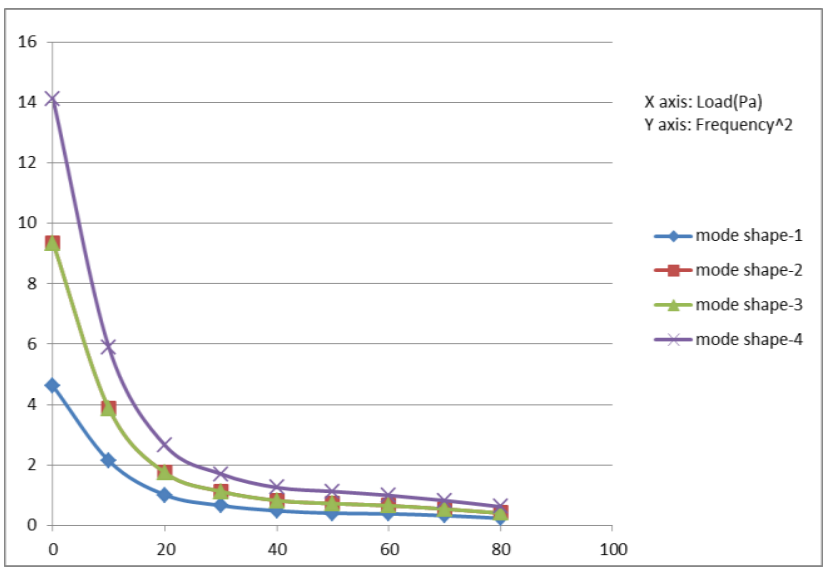

Fig 10: Frequency versus thermal loads.

From the above results we can conclude that there is fall of the frequency due to rise in temperature which tells us that the temperature increase can also make the plate buckle as we can see from the above figures. The curve is not linear.

\section{CONCLUSION}

Buckling loads of plate and shell have been interpreted by vibration correlation technique. Finite element method was used to calculate loads under compression which was compared with the results obtained through VCT. The results are in good agreement with the experimental and analytical results. In this report we found its (VCT) validation with a submarine hull. And for the thermal buckling analysis the similar results were seen, where the results correlated well. However, the curve obtained was not linear, which we are expecting to overcome in future with an improved version of VCT. The VCT was applied using ANSYS. The actual buckling was estimated by EIGEN BUCKLING in ANSYS. The modal behavior of the structures was investigated using MODAL analysis in ANSYS. Natural frequencies of the structures were recorded as a function of the applied axial compression load and were correlated.

\section{REFERENCES}

1. Uday Ranjan Goud, Dr. N. V. Swamy Naidu, Investigation on Buckling of Laminated Composite Plate, IOSR Journal of Mechanica and Civil Engineering (IOSR-JMCE), e-ISSN: 2278-1684, p-ISSN 2320-334X PP 81-87, DOI: 10.9790/1684-16053048187, www.iosrjournals.org

2. H. Abramovich, D. Govich, A. Grunwald, Buckling predictions of panels using vibration correlation technique, Elsevier journal.

3. Parthasarathy Garre, M. Satyanarayana Gupta Investigation of Structural Strength on Sandwich Panel of Fiber Reinforced Composite. International Journal of Civil Engineering \& Technology (IJCIET) 2015

4. Inman, Daniel J., "Engineering Vibrations, Second Edition," Prentice Hall, New Jersey, 2001.

5. Singer J, Arbocz J, Weller T, Buckling experiments: experimental methods in buckling of thin-walled structure: shells, build-up structures and additional topics. Vibration Correlation technique, vol. 2 John Wiley \& Sons, Inc 2002.

6. Manikonda Ganesh, C Nandini , M Rakesh Reddy, B Siva Kumar, M Chaitanya modeling and analysis of outer shell of cruise missile. IJRET 2016

7. H. Lurie, Lateral vibrations as related to structural stability (Ph. D thesis), California Institute of technology, Pasadena, California, 1950. 
8. Plaut RH, Virgin LN. Use of frequency data to predict buckling J. Eng. Mech. 1990.

9. Virgin LN, Plaut RH. Effect of axial load on for CED vibrations of beams. J. sound Vib. 1993.

10. Dr. S. Srinivasa Prasad, Madhavi Nagi Reddy Finite Element Modeling and Analysis of CFRP Composite Stiffened Panels for Post Buckling Behavior. IJERT 2016

11. L.N. Virgin, R.H. Plaut, C.E. Via, Axial load effects on the frequency response of a clamped beam, Proceedings of the 21st IMAC Conference and Explosion 2003 (IMAC XXI): A conference and explosion on structural dynamics,3-6 february 2003, Kissimmee, florida.

12. T.A. Alexander, The relationship between the buckling load factor and the fundamental frequency of a structure, Structures Congress 2005, New York, United States.

13. Singer J. Abramovich H. Vibration correlation techniques for definition of practical boundary conditions in stiffened shells, AIAA J.

14. Rosen A, Singer J. Effect of axisymmetric imperfections on the vibrations of cylindrical shells.

15. Supasak, C, 2005. Comparison of buckling loads of thin plates by experiment method. Master Thesis, Mechanical Engineering Department, Chulalong korn University, Bangkok, Thailand.

16. Chai, G.B., Banks, W.M., and Rhodes, J., 1991. An experiment study on laminated panels in compression. Composite Structures, Vol. 19, No. 1, pp. 67-87.

17. Tuttle, M., Singhatanadgid, P., and Hinds, G, Buckling of composite panels subjected to biaxial loading. Experiment Mechanics, Vol. 39, No. 3, pp.191-201, 1999

18. Lurie, H. and Monica, S., 1952. Lateral vibrations as related to structural stability. Journal of Applied Mechanics, pp. 195-204.

19. Chailleux, A., Hans, Y., and Verchery, G. 1975. Experimental study of the buckling of laminated composite columns and plates. Journal of Mechanical Sciences, Vol. 17, pp. 489-498.

20. Pannok, C. and Singhatanadgid, P., 2006 Buckling analysis of composite laminate skew plates with various edge support conditions Proceedings of the 20thConference of the Mechanical Engineering Network of Thailand(ME-NETT 20), Nakhon Ratchasima, Thailand. 18-20 October 2006.

21. Weaver Jr., W, Timoshenko, S.P., and Young, D.H.1990. Vibration problems in engineering. Wiley, New York, USA.

\section{AUTHORS PROFILE}

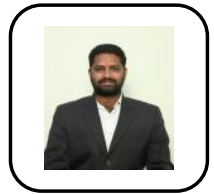

Nayani Uday Ranjan Goud, Assistant Professor, Department of Aeronautical Engineering MLR Institute of Technology, Dundigal, Hyderabad, Telangana, India, and he have completed his M.Tech in Aerospace Engineering.

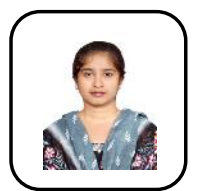

Alka Sawale, Assistant Professor, Department of Aeronautical Engineering MLR Institute of Technology, Dundigal, Hyderabad, Telangana, India, and she have completed her M.Tech in Aerospace Engineering.

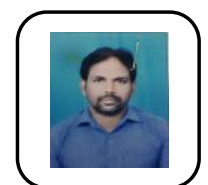

Bhupal Rakham, Assistant Professor, Department of Aeronautical Engineering MLR Institute of Technology, Dundigal, Hyderabad, Telangana, India, and he have completed his M.Tech in Aerospace Engineering. 